Check for updates

Cite this: RSC Adv., 2019, 9, 26209

Accepted 9th August 2019

DOI: 10.1039/c9ra05482k

rsc.li/rsc-advances

\title{
Asymmetric retro-[1,4]-Brook rearrangement of 3- silyl allyloxysilanes via chirality transfer from silicon to carbon $\uparrow$
}

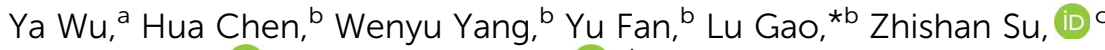 \\ Changwei $\mathrm{Hu}$ (D) $^{c}$ and Zhenlei Song (D)*b
}

An asymmetric retro-[1,4]-Brook rearrangement of 3-silyl allyloxysilanes has been developed via Si-to-C chirality transfer. Mechanistic studies reveal that the silyl group migrates with retention of configuration. The stereochemical outcome of the newly formed stereogenic carbon center, which has remained a longstanding question, is also clarified, suggesting a diastereoselective Si to C chirality transfer without loss of enantiomeric excess.

\section{Introduction}

Intramolecular O-to-C silyl migration, now called retro-Brook (or West) rearrangement, was first reported by Speier and later systematically studied by West. ${ }^{1}$ The retro-Brook rearrangement occurs only under special circumstances ${ }^{2}$ and so has been less investigated than Brook rearrangement. ${ }^{3}$ But, it comprises a powerful synthetic tool because diverse organosilanes could be constructed from more accessible silyl ethers by a rapid and regio- and stereoselective manner. A covalent $\mathrm{Si}-\mathrm{O}$ bond is cleaved and a $\mathrm{Si}-\mathrm{C}$ bond is formed via silyl migration. Thus, the stereochemical courses at the migrating silicon center and the stereochemical control at the forming carbon center comprise two important stereochemical issues. Tomooka and co-workers ${ }^{4}$ reported the first example of practically useful level of retro$[1,4]$-Brook rearrangement of allyloxysilane by use of HMPA as a co-solvent. In this work, they also showed, for the first time, that the silyl migration proceeded with retention of configuration at the silicon center (Scheme 1). In contrast, more efforts have been directed toward diastereoselective formation of the $\mathrm{Si}-\mathrm{C}$ bond to generate synthetically useful chiral organosilanes. Nearly all previous studies have used stereogenic $\mathrm{C} 1,{ }^{2 b, d, e} \mathrm{C} 2$ (ref. $2 h$ ) or $\mathrm{C} 3$ (ref. $2 a$ and $j$ ) centers in substrate $\mathbf{I}$ to control

${ }^{a}$ Department of Biological and Chemical Engineering, Chongqing University of Education, Chongqing 400067, China

${ }^{b}$ Sichuan Engineering Laboratory for Plant-Sourced Drug, Research Center for Drug Industrial Technology, Key Laboratory of Drug-Targeting and Drug Delivery System of the Education Ministry, West China School of Pharmacy, Sichuan University, Chengdu, 610041, China. E-mail: lugao@scu.edu.cn; zhenleisong@scu.edu.cn

'Key Laboratory of Green Chemistry \& Technology, Ministry of Education, College of Chemistry, Sichuan University, Chengdu, 610064, China

$\dagger$ Electronic supplementary information (ESI) available: Experimental procedures, characterisation data for new compounds. CCDC 1901967 and 1901968. For ESI and crystallographic data in CIF or other electronic format see DOI: $10.1039 / \mathrm{c} 9 \mathrm{ra} 05482 \mathrm{k}$ diastereoselective formation of the $\mathrm{Si}-\mathrm{C}$ bond in III. When the migrating silicon is stereogenic, ${ }^{5}$ it might be used as a stereochemical controller by $\mathrm{Si}$ to $\mathrm{C}$ chirality transfer, which was redefined by Oestreich. ${ }^{6}$ Achieving this in practice is quite challenging. There are only two examples we know come from a preliminary study by Tomooka and co-workers. ${ }^{4}$ The 3 -Me allyloxysilane with SiOMePht-Bu as the migrating silyl group afforded a dr of $83: 17$, while the corresponding 3 -SiMe 3 allyloxysilane only migrated with a dr of $66: 34$. In both cases, the stereochemistry of the formed stereogenic carbon center were not determined.

Oestreich rationalized the difficulties in achieving high diastereoselectivity during Si-to-C chirality transfer as follows. ${ }^{6}$ The relatively long $\mathrm{Si}-\mathrm{C}$ bond disfavors formation of a compact transition state II, which weakens diastereoselectivity. At the same time, all three substituents on the migrating silyl group can affect the stereochemical course, requiring the careful selection of three substituents that together allow efficient stereochemical control. Despite these difficulties, Oestreich described an intermolecular Pd- catalyzed asymmetric hydrosilylation using chiral silane (Scheme 2a), ${ }^{7}$ and Leighton demonstrated an intramolecular Hosomi-Sakuraiallylation involving a chiral allylsilane intermediate (Scheme $2 \mathrm{~b}$ ). ${ }^{8}$ In both

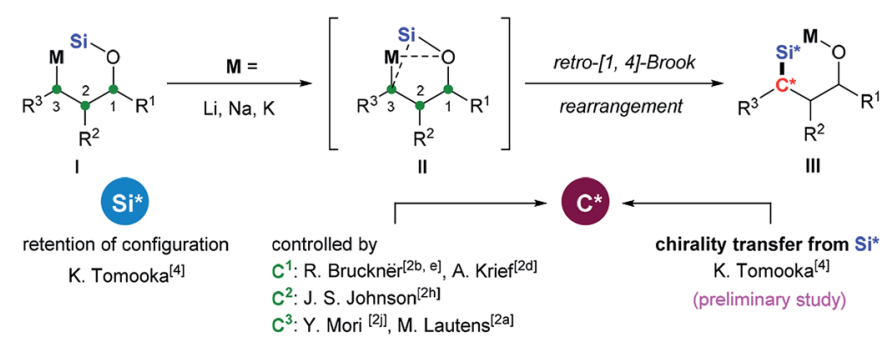

Scheme 1 Diastereoselective retro-Brook rearrangement. 


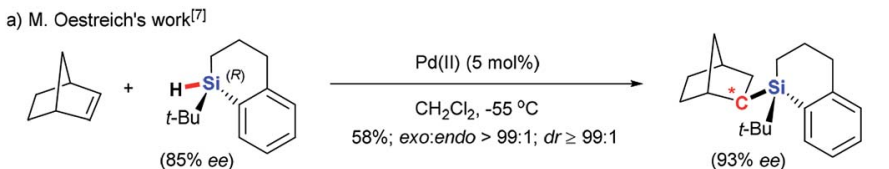

b) J. L. Leighton's work ${ }^{[8]}$

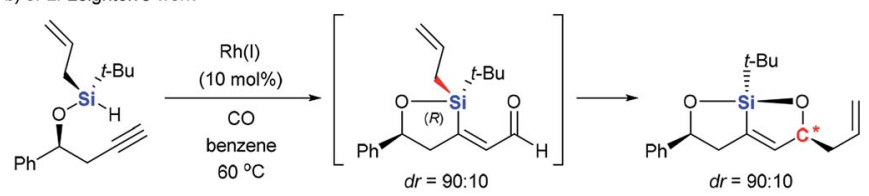

c) This work

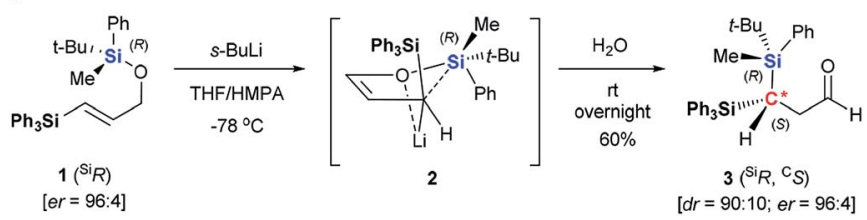

Scheme 2 Chirality Transfer from Silicon to Carbon.

of these cases, either cyclic silanes or acyclic silane with three distinct, sterically demanding substituents were used to achieve the high stereochemical control.

Here we report an asymmetric retro-[1,4]-Brook rearrangement of 3-silyl allyloxysilanes $\mathbf{1}$ via an efficient Si-to-C chirality transfer (Scheme 2c). The combination of SiMePht-Bu as the migrating silyl group and $\mathrm{SiPh}_{3}$ as the terminal silyl group proved most effective, giving geminal bis(silyl) aldehyde 3 and enol derivatives 4 in good yield with high diastereoselectivity. The overall stereochemical outcome of the migrating silicon center and the newly formed carbon center were clarified by detailed mechanistic studies.

\section{Results and discussion}

This project arose from our interest in developing chiral geminal bis(silanes) reagents and synthons. ${ }^{9}$ These species contain two different silyl groups, making the carbon to which they are attached a stereogenic center. In previous work, we achieved asymmetric $\mathrm{C}-\mathrm{C}$ or $\mathrm{C}-\mathrm{H}$ bonds formation via 3,3sigma tropic rearrangement of optically pure 3,3-bis(silyl) allylic alcohols, allowing asymmetric synthesis of crotyl geminal bis(silanes). ${ }^{\mathbf{1 0}}$ We were curious whether asymmetric $\mathrm{C}-\mathrm{Si}$ bond formation could be another efficient strategy to construct chiral geminal bis(silanes). Our $s$-BuLi-promoted retro-[1,4]-Brook rearrangement of 3-silyl allyloxysilanes ${ }^{\mathbf{1 1}}$ appeared to be a suitable model to test this possibility. The reaction tolerates a wide range of migrating and non-migrating silyl groups, making it practical for identifying the best pair of silyl groups.

We initially fixed $t$-BuPhMeSi as the migrating silyl group (Table 1). Entries 1-7 showed an obvious steric bias for the nonmigrating silicons $\left(\mathrm{Si}^{1}\right)$ at the 3-position of $\mathbf{1}$. When $\mathrm{Si}^{1}$ was an $\mathrm{SiMe}_{3}$ group, geminal bis(silyl) aldehydes 3a were generated as a nearly $1: 1$ mixture of two diastereomers (entry 1). Even when one methyl was replaced with a phenyl group, dr did not improve for the corresponding products $\mathbf{3 b}$ (entry 2). These results imply that the small methyl group does not permit good
Table 1 Screening of Silyl Groups ${ }^{a}$

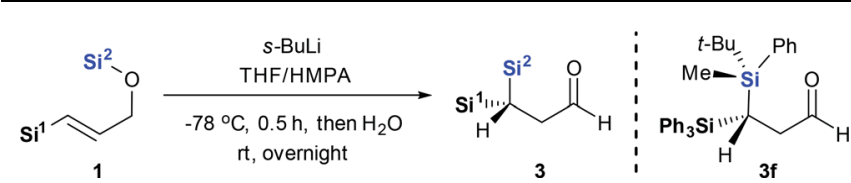

\begin{tabular}{lllllll} 
Entry & Sub. & $\mathrm{Si}^{1}$ & $\mathrm{Si}^{2}$ & Prod. & Yield $^{b}$ & $\mathrm{dr}^{c}$ \\
\hline 1 & $\mathbf{1 a}$ & $\mathrm{Me}_{3} \mathrm{Si}$ & $t$-BuPhMeSi & $\mathbf{3 a}$ & $62 \%$ & $56: 44$ \\
2 & $\mathbf{1 b}$ & $\mathrm{Me}_{2} \mathrm{PhSi}$ & $t$-BuPhMeSi & $\mathbf{3 b}$ & $65 \%$ & $47: 53$ \\
3 & $\mathbf{1 c}$ & $\mathrm{Et}_{3} \mathrm{Si}$ & $t$-BuPhMeSi & $\mathbf{3 c}$ & $53 \%$ & $67: 33$ \\
4 & $\mathbf{1 d}$ & $(n-\mathrm{Pr})_{3} \mathrm{Si}$ & $t$-BuPhMeSi & $\mathbf{3 d}$ & $50 \%$ & $65: 35$ \\
5 & $\mathbf{1 e}$ & $(\mathrm{i}-\mathrm{Pr})_{3} \mathrm{Si}$ & $t$-BuPhMeSi & $\mathbf{3 e}$ & $45 \%$ & $83: 17$ \\
6 & $\mathbf{1 f}$ & $\mathrm{Ph}_{3} \mathrm{Si}$ & $t$-BuPhMeSi & $\mathbf{3 f}$ & $60 \%$ & $90: 10$ \\
7 & $\mathbf{1 g}$ & $\mathrm{Ph}_{3} \mathrm{Si}$ & 1-NpPhMeSi & $\mathbf{3 g}$ & $65 \%$ & $65: 35$ \\
8 & $\mathbf{1 h}$ & $\mathrm{Et}_{3} \mathrm{Si}$ & 1-NpPhMeSi & $\mathbf{3 h}$ & $73 \%$ & $83: 17$ \\
9 & $\mathbf{1 i}$ & $\mathrm{Me}_{3} \mathrm{Si}$ & 1-NpPhMeSi & $\mathbf{3 i}$ & $63 \%$ & $86: 14$ \\
10 & $\mathbf{1 j}$ & $t$-BuPhMeSi & $\mathrm{Ph}_{3} \mathrm{Si}$ & $\mathbf{3 f}$ & $55 \%$ & $74: 26$
\end{tabular}

${ }^{a}$ Reaction conditions: 1 (0.15 mmol), s-BuLi (0.60 mmol), HMPA (0.6 mmol), $0.5 \mathrm{~mL}$ of THF, at $-78{ }^{\circ} \mathrm{C}$ for $0.5 \mathrm{~h}$, then $\mathrm{H}_{2} \mathrm{O}$ at rt overnight. ${ }^{b}$ Isolated yields. ${ }^{c}$ Ratios were determined from ${ }^{1} \mathrm{H}$ NMR analysis of crude product.

diastereochemical control. Diastereoselectivity improved progressively when steric demand at $\mathrm{Si}^{1}$ increased from $\mathrm{SiMe}_{3}$ to $\mathrm{SiEt}_{3}, \mathrm{Si}(n-\mathrm{Pr})_{3}, \mathrm{Si}(\mathrm{i}-\mathrm{Pr})_{3}$ and finally $\mathrm{SiPh}_{3}$ (entries 3-6). The largest $\mathrm{SiPh}_{3}$ group imposed the strongest stereochemical control, providing 3f at the highest dr of $90: 10$ (entry 6). Interestingly, an inverse steric bias for $\mathrm{Si}^{1}$ was observed when the migrating silicon was switched from $t$-BuPhMeSi to 1NpPhMeSi. The largest $\mathrm{SiPh}_{3}$ group afforded a dr of only $65: 35$, while the smallest $\mathrm{SiMe}_{3}$ provided the best dr of $86: 14$ (entries 7-9). We also tested the silicon combination in which the $t$ BuPhMeSi functioned as a chiral auxiliary, while $\mathrm{SiPh}_{3}$ migrated (entry 10). The reaction gave the aldehyde $3 \mathbf{f}$ with a dr of $74: 26$ lower than that obtained in entry 5 .

Next we examined the scope of electrophiles for quenching the lithium enolate intermediate generated from 1f. The reaction tolerated triethylsilyl chloride (entry 1), various acyl chlorides (entries 2-9) and chlorocarbonates (entries 10 and 11) to provide 3,3-bis(silyl) enol derivatives 4 in good yields with high diastereoselectivity (Table 2). The enol double bond formed exclusively with $Z$-selectivity. The relative stereochemistry of the products was unambiguously established based on X-ray diffraction analysis of $\mathbf{4 d}$ crystals. ${ }^{12}$ Methyl iodide was also a suitable electrophile, but less reactive than acyl chloride, giving 41 in $40 \%$ yield with $O$-alkylation selectivity (entry 12 ).

The silicon can migrate with either retention or inversion of configuration. Thus, the relative stereochemistry of $\mathbf{3 f}$ may not reflect the stereochemical course of the migrating silicon, or how it controls the stereochemical outcome of the resulting stereogenic carbon center. In particular, if the enantiomerically defined silyl group racemizes during migration, the carbon center can be constructed diastereoselectively, but not enantioselectively. The observation by Tomooka and co-workers that silicon migrates with retention of configuration in their simple allyloxy system ${ }^{4}$ does not necessarily apply to our case, since the 
Table 2 Scope of Electrophiles ${ }^{a}$

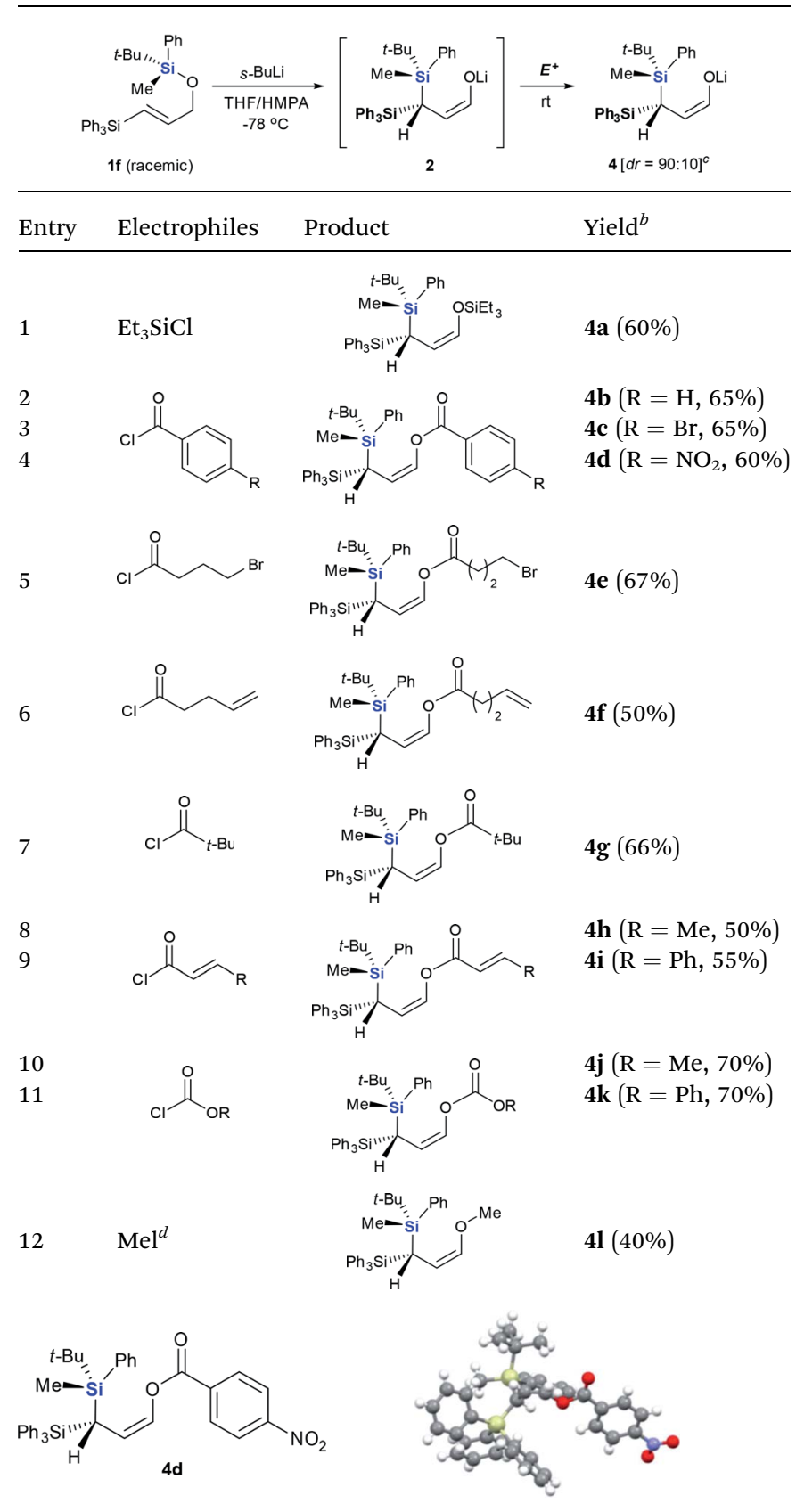
${ }^{a}$ Reaction conditions: 1 f $(0.15 \mathrm{mmol}), s$-BuLi $(0.60 \mathrm{mmol})$, HMPA $(0.6$
mmol), $0.5 \mathrm{~mL}$ of THF, at $-78{ }^{\circ} \mathrm{C}$ for $0.5 \mathrm{~h}$, then electrophile at rt for
$2 \mathrm{~h}$. ${ }^{b}$ Isolated yields. ${ }^{c}$ Ratios were determined from crude ${ }^{1} \mathrm{H}$ NMR
analysis of product. ${ }^{d} 10.0$ equiv. of MeI.

non-migrating silicon may affect the stereochemical course. To gain a definitive answer to this question, we used enantiomerically defined $\mathbf{1 0}$ as a stereochemical probe (Scheme 3). ${ }^{\mathbf{1 3}}$ Following the procedure developed by Oestreich, ${ }^{14}$ a $1: 1$ mixture of 5 was separated by several cycles of silica gel chromatography, affording 6 in diastereomerically pure form. Reduction of 6 with DIBAL-H provided hydrosilane 7 in $77 \%$ yield. Subsequent chlorination of 7 with $\mathrm{CCl}_{4}$ delivered
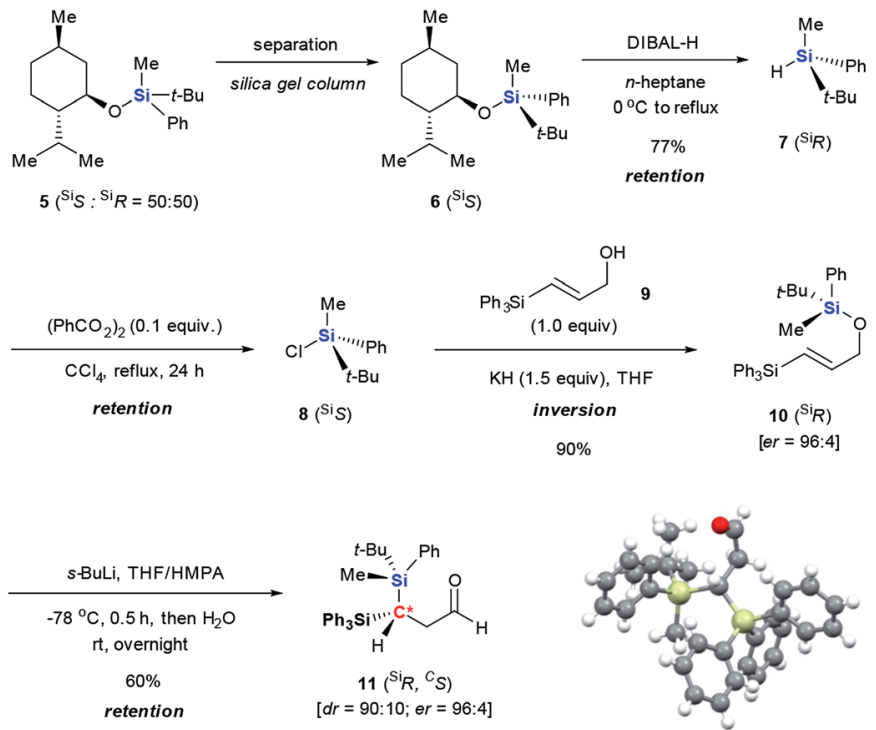

Scheme 3 Preparation of enantiomerically defined 10 and its retro$[1,4]$-Brook rearrangement to form 11.

chlorosilane 8 , which directly reacted with the potassium salt of 9, giving 10 in 90\% yield. The high er of 10 (96:4) suggests that transformation from $\mathbf{6}$ to $\mathbf{1 0}$ proceeds in a stereospecific manner at the silicon center, and should follow the known sequence of retention-retention-inversion. ${ }^{15}$ Thus, the absolute configuration of the silicon in $\mathbf{1 0}$ was assigned as $R$. Under the optimal retro-[1,4]-Brook rearrangement conditions, 10 was converted into aldehyde 11. The major isomer showed an er of $96: 4$, indicating that the silicon migrated stereospecifically. Xray diffraction analysis of $\mathbf{1 1}^{\mathbf{1 6}}$ unambiguously confirmed the $R$ configuration of the silicon, indicating that migration proceeds with retention of configuration as in Tomooka's case. The X-ray diffraction analysis of $\mathbf{1 1}$ also established the $S$-configuration of the new stereogenic carbon center. The result revealed that the migration proceeded by a diastereoselective Si to $\mathrm{C}$ chirality transfer without loss of enantiomeric excess.

A plausible mechanism to explain our results is proposed in Scheme 4, based on the model we proposed for the racemic version of the reaction. ${ }^{\mathbf{1 1}}$ The $\alpha$-deprotonation of $\mathbf{1 0}$ gives the corresponding allylic anion, which adopts the endo-orientation assisted by $\mathrm{Li}-\mathrm{O}$ coordination. ${ }^{17}$ The $\mathrm{O}$-to-C silyl migration takes place irreversibly via two possible pentacoordinated silicate transition states or intermediates, TS-1 and TS-2. ${ }^{18}$ In this way, the configuration of the silicon center is retained without

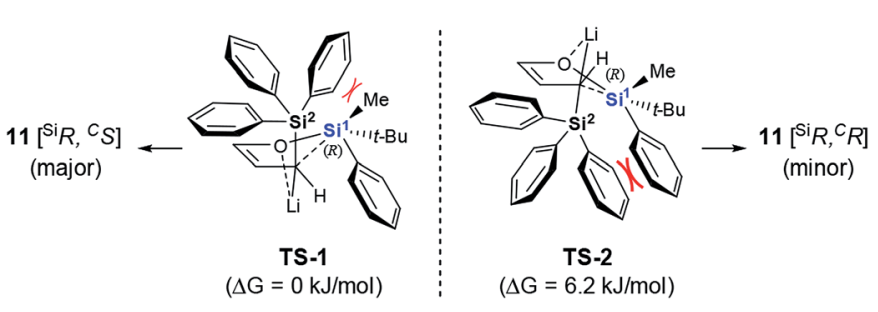

Scheme 4 Plausible reaction mechanism. 
racemization. While TS-2 suffers a severely steric repulsion between the $\mathrm{Ph}$ group on $\mathrm{Si}^{1}$ and one of the $\mathrm{Ph}$ groups on $\mathrm{Si}^{2}$, the interaction between the Me group on $\mathrm{Si}^{1}$ and the $\mathrm{Ph}$ group on $\mathrm{Si}^{2}$ appears being tolerable in the case of TS-1. These considerations are supported by the preliminary results from density functional theory calculations, which showed TS-1 to be more stable than TS-2 by $6.2 \mathrm{~kJ} \mathrm{~mol}^{-1}$. Our model also explains the observed steric bias for substituents on $\mathrm{Si}^{1}$. Substituents smaller than the Ph group might not be large enough to create an appreciable difference between the non-bonded interaction with the Me group in TS-1 and with the Ph group in TS-2. As a result, 3 forms with poor diastereoselectivity (Table 1, entries 1-4).

\section{Conclusions}

In summary, Si-to-C chirality transfer has been used as an efficient strategy to achieve asymmetric retro-[1,4]-Brook rearrangement of 3-silyl allyloxysilanes. The $\mathrm{SiMePh} t$-Bu and $\mathrm{SiPh}_{3}$ groups, in which SiMePht-Bu migrates, function as the best combination to give geminal bis(silyl) aldehyde and enol derivatives with high diastereoselectivity. The silyl group migrates with retention of configuration. Enantioselective generation of the stereogenic carbon center suggests that Si-to$\mathrm{C}$ chirality transfer is a promising method to construct optically pure chiral organosilanes. Further applications of this strategy are being explored in our group.

\section{Conflicts of interest}

There are no conflicts to declare.

\section{Acknowledgements}

We are grateful for financial support from the NSFC (21622202, 21502125).

\section{Notes and references}

1 (a) J. L. Speier, J. Am. Chem. Soc., 1952, 74, 1003; (b) R. West, R. Lowe, H. F. Stewart and A. Wright, J. Am. Chem. Soc., 1971, 93, 282.

2 (a) M. Lautens, P. H. M. Delanghe, J. B. Goh and C. H. Zhang, J. Org. Chem., 1992, 57, 3270; (b) C. Gibson, T. Buck, M. Noltemeyer and R. Brückner, Tetrahedron Lett., 1997, 38, 2933; (c) T. N. Mitchell, M. Schtüze and F. Gießelmann, Synlett, 1997, 183; (d) J. Bousbaa, F. Ooms and A. Krief, Tetrahedron Lett., 1997, 38, 762; (e) C. Gibson, T. Buck, M. Walker and R. Brückner, Synlett, 1998, 201; $(f)$ T. N. Mitchell and M. Schütze, Tetrahedron, 1999, 55, 1285; (g) B. M. Comanita, S. Woo and A. G. Fallis, Tetrahedron Lett., 1999, 40, 5283; (h) M. R. Nahm, X. L. Hu, J. R. Potnick, C. M. Yates, P. S. White and J. S. Johnson, Angew. Chem., Int. Ed., 2005, 44, 2377; (i) E. N. Onyeozili and R. E. Maleczka, Tetrahedron Lett., 2006, 47, 6565; (j) Y. Mori, Y. Futamura and K. Horisaki, Angew. Chem., Int. Ed., 2008, 47, 1091; (k) J. A. Brekan, D. Chernyak,
K. L. White and K. A. Scheidt, Chem. Sci., 2012, 3, 1205; (l) Y. P. He, H. T. Hu, X. G. Xie and X. G. She, Tetrahedron, 2013, 69, 559; $(m)$ Y. P. He, B. Ma, J. Yang, X. G. Xie and X. G. She, Tetrahedron, 2013, 69, 5545; (n) V. Bariak, A. Malastová, A. Almássy and R. Šebesta, Chem.-Eur. J., 2015, 21, 13445; (o) Y. J. Kwon, Y. K. Jeon, H. B. Sim, I. Y. Oh, I. Shin and W. S. Kim, Org. Lett., 2017, 19, 6224; (p) L. Biancalana, S. Zacchini, N. Ferri, M. G. Lupo, G. Pampaloni and F. Marchetti, Dalton Trans., 2017, 46, 16589.

3 For reviews, see: (a) A. G. Brook, Acc. Chem. Res., 1974, 7, 77; (b) P. C. Bulman-Page, S. S. Klair and S. Rosenthal, Chem. Soc. Rev., 1990, 19, 147; (c) P. Jankowski, P. Raubo and J. Wicha, Synlett, 1994, 985; (d) M. A. Brook, Silicon in Organic, Organometallic, and Polymer Chemistry, John Wiley and Sons, New York, 2000; (e) W. H. Moser, Tetrahedron, 2001, 57, 2065; (f) M. Kira and T. Iwamoto, The Chemistry of Organic Silicon Compounds, Z. Rappoport and Y. Apeloig, ed. John Wiley and Sons, New York, 2001, pp. 853-948; $(g)$ E. Schaumann and A. Kirschning, Synlett, 2007, 177; $(h)$ A. B. Smith and C. M. Adams, Acc. Chem. Res., 2004, 37, 365; (i) H. J. Zhang, D. L. Priebbenow and C. Bolm, Chem. Soc. Rev., 2013, 42, 8540; (j) M. Sasaki and K. Takeda, Molecular Rearrangements in Organic Synthesis, ed. C. M. Rojas, John Wiley and Sons: New York, 2015, pp. 151-183; (k) G. Eppe, D. Didier and I. Marek, Chem. Rev., 2015, 115, 9175.

4 A. Nakazaki, T. Nakai and K. Tomooka, Angew. Chem., Int. Ed., 2006, 45, 2235.

5 For reviews of enatioselective generation of stereogenic silicon center, see: (a) M. Oestreich, Synlett, 2007, 1629; (b) L. W. Xu, L. Li, G. Q. Lai and J. X. Jiang, Chem. Soc. Rev., 2011, 40, 1777; (c) L. W. Xu, Angew. Chem., Int. Ed., 2012, 51, 12932; (d) Y. Wu, L. Gao and Z. L. Song, Chem. Bull., 2015, 78, 676; (e) R. Shintani, Asian J. Org. Chem., 2015, 4, 510; $(f)$ J. O. Bauer and C. Strohmann, Eur. J. Inorg. Chem., 2016, 2868; (g) Y. M. Cui, Y. Lin and L. W. Xu, Coord. Chem. Rev., 2017, 330, 37. For selected progresses, see: $(h)$ K. Igawa, J. Takada, T. Shimono and K. Tomooka, J. Am. Chem. Soc., 2008, 130, 16132; (i) Y. Yasutomi, H. Suematsu and T. Katsuki, J. Am. Chem. Soc., 2010, 132, 4510; (j) R. Shintani, H. Otomo, K. Ota and T. Hayashi, J. Am. Chem. Soc., 2012, 134, 7305; (k) J. O. Bauer and C. Strohmann, Angew. Chem., Int. Ed., 2014, 53, 720; (l) R. Shintani, C. Takagi, T. Ito, M. Naito and K. Nozaki, Angew. Chem., Int. Ed., 2015, 54, 1616; $(m)$ R. Shintani, R. Takano and K. Nozaki, Chem. Sci., 2016, 7, 1205; (n) L. Chen, J. B. Huang, Z. Xu, Z. J. Zheng, K. F. Yang, Y. M. Cui, J. Cao and L. W. Xu, RSC Adv., 2016, 6, 67113; (o) K. Igawa, D. Yoshihiro, Y. Abe and K. Tomooka, Angew. Chem., Int. Ed., 2016, 55, 5814; (p) Q. W. Zhang, K. An, L. C. Liu, Q. Zhang, H. F. Guo and W. He, Angew. Chem., Int. Ed., 2017, 56, 1125; (q) X. F. Bai, J. F. Zou, M. Y. Chen, Z. Xu, L. Li, Y. M. Cui, Z. J. Zheng and L. W. Xu, Chem.-Asian J., 2017, 12, 1730; (r) Y. Sato, C. Takagi, R. Shintani and K. Nozaki, Angew. Chem., Int. Ed., 2017, 56, 9211; $(s)$ G. Zhan, H. L. Teng, Y. Luo, S. J. Lou, M. Nishiura and 
Z. M. Hou, Angew. Chem., Int. Ed., 2018, 57, 12342; $(t)$ H. Chen, Y. Chen, X. X. Tang, S. F. Liu, R. P. Wang, T. B. Hu, L. Gao and Z. L. Song, Angew. Chem., Int. Ed., 2019, 58, 4695.

6 M. Oestreich, Chem.-Eur. J., 2006, 12, 30.

7 (a) M. Oestreich and S. Rendler, Angew. Chem., Int. Ed., 2005, 44, 1661; (b) S. Rendler and M. Oestreich, Beilstein J. Org. Chem., 2007, 3, 9.

8 D. R. Schmidt, S. J. O'Malley and J. L. Leighton, J. Am. Chem. Soc., 2003, 125, 1190.

9 (a) Q. Luo, C. Wang, Y. X. Li, K. B. Ouyang, L. Gu, M. Uchiyama and Z. F. Xi, Chem. Sci., 2011, 2, 2271; (b) H. Li, L. T. Liu, Z. T. Wang, F. Zhao, S. G. Zhang, W. X. Zhang and Z. F. Xi, Chem.-Eur. J., 2011, 17, 7399; (c) K. Groll, S. M. Manolikakes, X. M. du Jourdin, M. Jaric, A. Bredihhin, K. Karaghiosoff, T. Carell and P. Knochel, Angew. Chem., Int. Ed., 2013, 52, 6776; (d) H. Y. Cui, J. Y. Zhang and C. M. Cui, Organometallics, 2013, 32, 1; (e) S. T. Ding, L. J. Song, L. W. Chung, X. H. Zhang, J. W. Sun and Y. D. Wu, J. Am. Chem. Soc., 2013, 135, 13835; $(f)$ V. Werner, T. Klatt, M. Fujii, J. Markiewicz, Y. Apeloig and P. Knochel, Chem.-Eur. J., 2014, 20, 8338; $(g)$ R. Shintani, H. Kurata and K. Nozaki, Chem. Commun., 2015, 51, 11378; (h) Z. X. Liu, H. C. Tan, T. R. Fu, Y. Xia, D. Qiu, Y. Zhang and J. B. Wang, J. Am. Chem. Soc., 2015, 137, 12800; (i) Z. J. Liu, X. L. Lin, N. Yang, Z. S. Su, C. W. Hu, P. H. Xiao, Y. Y. He and Z. L. Song, J. Am. Chem. Soc., 2016, 138, 1877; (j) T. Kosai, S. Ishida and T. Iwamoto, Angew. Chem., Int. Ed., 2016, 55, 15554; (k) M. Das, A. Manvar, M. Jacolot, M. Blangetti, R. C. Jones and D. F. O'Shea, Chem.-Eur. J., 2015, 21, 8737; (l) M. Das and D. F. O'Shea, Org. Lett., 2016, 18, 336; $(m)$ Y. Mizuhata, S. Fujimori, T. Sasamori and N. Tokitoh, Angew. Chem., Int. Ed., 2017, 56, 4588; (n) H. Kinoshita, A. Ueda, H. Fukumoto and K. Miura, Org. Lett., 2017, 19, 882; (o) Y. B. Zhang, Q. Y. Guo, X. W. Sun, J. Lu, Y. J. Cao, Q. Pu, Z. W. Chu, L. Gao and Z. L. Song, Angew. Chem., Int. Ed., 2018, 57, 942; (p) H. Hazrati and M. Oestreich, Org. Lett., 2018, 20, 5367; (q) S. Xu, R. Chen, Z. H. Fu, Y. P. Gao and J. B. Wang, J. Org. Chem., 2018, 83, 6186; (r) M. H. Yang, J. Lian, W. Sun, T. Z. Qiao and
S. F. Zhu, J. Am. Chem. Soc., 2019, 141, 4579; (s) J. Guo, H. L. Wang, S. P. Xing, X. Hong and Z. Lu, Chem, 2019, 5, 881. 10 (a) Z. W. Chu, K. Wang, L. Gao and Z. L. Song, Chem. Commun., 2017, 53, 3078; (b) Y. Chu, Q. Pu, Z. X. Tang, L. Gao and Z. L. Song, Tetrahedron, 2017, 73, 3707.

11 Z. L. Song, Z. Lei, L. Gao, X. Wu and L. J. Li, Org. Lett., 2010, 12, 5298.

12 CCDC 1901967 [4d] contains the supplementary crystallographic data for this paper. $\dagger$

13 (a) S. Rendler, M. Oestreich, C. P. Butts and G. C. LloydJones, J. Am. Chem. Soc., 2007, 129, 502; (b) S. Rendler and M. Oestreich, Angew. Chem., Int. Ed., 2008, 47, 5997; (c) K. Igawa, D. Yoshihiro, N. Ichikawa, N. Kokan and K. Tomooka, Angew. Chem., Int. Ed., 2012, 51, 12745; (d) T. T. Metsänen, P. Hrobárik and M. Oestreich, J. Am. Chem. Soc., 2014, 136, 6912; (e) T. Fallon and M. Oestreich, Angew. Chem., Int. Ed., 2015, 54, 12488.

14 V. T. Trepohl, R. Fröhlich and M. Oestreich, Tetrahedron, 2009, 65, 6510.

15 Reduction of $(R)-\mathbf{1 0}$ with DIBAL-H giving $(S)-7$ in $81 \%$ yield. This result supports that the configuration of the silicon center in 10 should be $R$. See ESI $\dagger$ for details.

16 CCDC 1901968 [11] contains the supplementary crystallographic data for this paper. $\dagger$

17 (a) W. C. Still and T. L. Macdonald, J. Am. Chem. Soc., 1974, 96, 5561; (b) M. Schlosser and S. Strunk, Tetrahedron, 1989, 45, 2649; (c) A. R. Katritzky, M. Piffl, H. Lang and E. Anders, Chem. Rev., 1999, 99, 665.

18 (a) A. Wright and R. West, J. Am. Chem. Soc., 1974, 96, 3227; (b) T. Kawashima, K. Naganuma and R. Okazaki, Organometallics, 1998, 17, 367; (c) K. Naganuma, T. Kawashima and R. Okazaki, Chem. Lett., 1999, 1139; (d) T. Kawashima, J. Organomet. Chem., 2000, 611, 256; (e) T. Kawashima, Bull. Chem. Soc. Jpn., 2003, 76, 471; $(f)$ E. P. A. Couzijn, M. Schakel, F. J. J. de Kanter, A. W. Ehlers, M. Lutz, A. L. Spek and K. Lammertsma, Angew. Chem., Int. Ed., 2004, 43, 3440; (g) Q. Liu, Y. Chen, X. Zhang, K. N. Houk, Y. Liang and A. B. Smith, J. Am. Chem. Soc., 2017, 139, 8710. 